\title{
Modeling Cash Plus Other Psychosocial and Structural Interventions to Prevent HIV Among Adolescent Girls and Young Women in South Africa (HPTN 068)
}

\author{
Marie C. D. Stoner ${ }^{1,2}$ (1) . Jessie K. Edwards ${ }^{3}$. Daniel Westreich ${ }^{3} \cdot$ Kelly Kilburn ${ }^{9} \cdot$ Jennifer Ahern ${ }^{8}$. \\ Sheri A. Lippman ${ }^{4,7}$. F. Xavier Gómez-Olivé ${ }^{4,5} \cdot$ Kathleen Kahn ${ }^{4,5,6}$. Audrey Pettifor ${ }^{2,3,4}$
}

Accepted: 8 January 2021 / Published online: 21 January 2021

(c) The Author(s) 2021, corrected publication 2021

\begin{abstract}
Poverty alleviation programs can reduce HIV incidence but may have greater impacts when combined with other psychosocial interventions. We modeled the change in HIV incidence among South African adolescent girls and young women (AGYW) associated with combining a cash transfer (the South African Child Support Grant (CSG)) with other structural and behavioral interventions. We modeled observational data from the HPTN 068 study where 2328 HIV negative AGYW (13-20 years) were followed for 4 years. In a Monte Carlo simulation based on this cohort $(\mathrm{N}=10,000)$, CSG receipt was not independently associated with HIV incidence. Providing the CSG combined with increasing caregiver care and reducing adolescent depression had the largest reduction in HIV incidence with the fewest number of combined interventions (RD - 3.0\%; (95\% CI - 5.1\%, - 0.9\%). Combining a monthly grant with interventions to increase caregiver care and reduce adolescent depression could substantially reduce HIV incidence above the provision of cash alone.
\end{abstract}

Keywords Adolescent girls $\cdot$ Young women $\cdot$ HIV prevention $\cdot$ Cash transfer $\cdot$ Social determinants $\cdot$ Causal inference

Marie C. D. Stoner

mcstoner@rti.org

1 Women's Global Health Imperative, RTI International, Berkeley, CA, USA

2 Carolina Population Center, University of North Carolina, Chapel Hill, NC, USA

3 Department of Epidemiology, University of North Carolina, Chapel Hill, NY, USA

4 MRC/Wits Rural Public Health and Health Transitions Research Unit (Agincourt), School of Public Health, Faculty of Health Sciences, University of the Witwatersrand, Johannesburg, South Africa

5 INDEPTH Network, Accra, Ghana

6 Epidemiology and Global Health Unit, Department of Public Health and Clinical Medicine, Umeå University, Umeå, Sweden

7 Department of Medicine, University of California, San Francisco, USA

8 Division of Epidemiology \& Biostatistics, School of Public Health, University of California, Berkeley, USA

9 Duke Global Health Institute, Duke University, Durham, NC, USA

\section{Introduction}

Cash transfer programs, where households or individuals receive cash payments, have been shown to mitigate the social determinants of HIV risk such as poverty and lack of education and to improve psychosocial outcomes including anxiety, self-esteem and hope for the future [1]. These programs are usually national government cash transfer or "social protection" programs provided to poor and vulnerable households to alleviate poverty and improve health outcomes. For example, the Child Support Grant (CSG) in South Africa is available to relatively low-income households to help parents with the costs of basic needs for their children without restrictions on how the money should be spent. Given the success of these programs in improving school attendance and increasing household expenditures, cash payments have increasingly been studied as a strategy to prevent HIV infection. The theory behind the use of these programs in HIV prevention is that improving the underlying structural factors related to HIV risk such as socioeconomic conditions and school attendance will reduce risky behaviors and therefore prevent HIV [2, 3]. Yet, most studies that have assessed the impact of cash transfer programs on HIV 
risk have shown mixed results among adolescent girls and young women (AGYW), a population with a relatively high incidence of HIV infection [3-6].

Four studies have evaluated the impact of cash transfer interventions on HIV biomarkers among AGYW with mixed results. These interventions have provided cash to individual girls and their households either unconditionally or conditional on a behavior such as attending school. A cash transfer intervention to AGYW and their families to stay in school in Malawi reduced HIV prevalence (OR 0.36; 95\% CI 0.14, 0.91 ) [4] and a recent intervention that provided incentives to AGYW to enroll and attend school in eSwatini reduced HIV incidence among those who received the incentives (OR 0.77; 95\% CI 0.60-0.98) [7]. Conversely, a third study in South Africa had too few HIV infections to assess impact [6] and a fourth study, from which these data originate, found no impact on HIV incidence among AGYW with a cash transfer intervention that was conditional on attending $80 \%$ of school days [5]. A larger number of studies have evaluated the effects of cash transfer programs on sexual behaviors among AGYW [8-13]. In particular, six of the eight studies of government grant programs that have evaluated impacts on sexual debut in adolescents found a delay in sexual initiative or a reduction in sexual onset, highlighting the potential of cash interventions for this age group [8-13].

In addition, recent evidence has shown that cash transfer programs might be more effective when combined with other interventions to provide psychosocial resources in addition to economic resources. Poverty is a social determinant of health that affects risk of HIV through complex pathways that intersect with other multilevel social factors. For example, one study in South Africa found that receipt of the government CSG reduced incidence of HIV-risk behaviors for girls aged 12-18 years (OR 0.63, p=0.02) but the reduction was larger when combining the CSG with teacher or caregiver support (as measured by a positive parenting scale including praise and warmth) (OR 0.55; 95\% CI $0.35-0.85$, P.0.01;) $[14,15]$. Still, only this one study has evaluated "cash plus" strategies for HIV prevention and the study examined associations with sexual behaviors, but not with HIV incidence $[14,15]$. Several additional cash plus care studies are currently ongoing but few are assessing impact on HIV incidence [16-23]. Among those that are examining incident infections [16, 19], these studies are limited to testing only select combinations (e.g. savingsled economic empowerment plus a family strengthening component) because of the high cost and large sample sizes required to implement randomized trials of multicomponent interventions.

The theory behind why these combined cash plus care interventions may be more effective is based on three main points [24]. First, sexual behaviors and HIV incidence among AGYW is related to multilevel and intersecting social factors at the level of the community, household, peers, and partner [25-28]. For example, economic instability is a driver of transactional sex, but is also associated with increased exposure to violence through a partner [29-32]. Second, the causal mechanisms by which different behaviors increase HIV-incidence may vary and intervening within more than one pathway could further reduce risk of HIV [24]. For example, age-disparate sex is increased by low school attendance [33], whereas unprotected sex is increased by power dynamics within a relationship $[34,35]$. Third, adversities accumulate throughout childhood and adolescence to increase risk of sexual transmitted infections more than any single adversity $[14,24,36]$. Thus, combination social protection has the potential to maximize HIV prevention impacts by ameliorating simultaneous risks across the life course within these intersecting areas.

We used data from AGYW in rural South Africa to explore the potential effects of different combinations of receipt of a government CSG plus increasing school attendance, reducing intimate partner violence (IPV), reducing adolescent depression, and increasing perceptions that a parent/caregiver cares on incident HIV infection. School attendance [37], intimate partner violence (IPV) [38], and depression [39] have all been associated with incident HIV infection in prior analyses of these data from the HIV Prevention Trial Network 068 study (HPTN 068). In addition, we examined if reductions in HIV incidence seen with the CSG plus other psychosocial and structural interventions were further increased or modified by receipt of the conditional cash transfer (CCT) intervention that was tested in the original HPTN 068 trial. We examined the potential effects of both the CSG and CCT but focus primarily on the CSG because prior studies have examined the CSG [14] and because the CCT did not have an impact in the initial trial, which may have been because so many households ( 80\%) were already receiving a government grant to alleviate poverty (the CSG) [5].

\section{Methods}

\section{Data}

We analyzed data from the main trial period of the HPTN 068 study from 2011 to 2015 . HPTN 068 was a randomized trial of an intervention to provide cash to AGYW and their households, conditional on $80 \%$ school attendance, as a way to prevent HIV acquisition in AGYW [5, 40]. The study enrolled 2533 AGYW aged 13-20 years who were in school, were not pregnant or married, had a parent/guardian in the household and were living in the rural Bushbuckridge subdistrict of Mpumalanga province, South Africa. The area is the site of the Agincourt Health and Socio-Demographic 
Surveillance System (HDSS) with high levels of poverty, migration for work, poor infrastructure (e.g. unpaved roads) and a high prevalence of HIV [41].

During the trial, young women were followed for up to 3 years until study completion or graduation from high school, whichever came first. AGYW were visited annually and each visit included an Audio Computer-Assisted Self-Interview (ACASI) with the AGYW and her parent/ guardian, and a test for HIV and Herpes Simplex Virus Type 2 (HSV-2). Our analysis includes only AGYW who had at least one follow-up visit and were HIV negative at enrollment.

\section{Variables}

The outcome of incident HIV infection was defined as new cases of HIV identified over the study period. New cases were defined as two reactive rapid tests with a confirmatory Western Blot. The exposures of interest were time-varying household receipt of a government CSG, baseline adolescent depression, baseline physical intimate partner violence, time-varying high attendance in school, time-varying caregiver care and randomization to the cash transfer treatment arm at baseline. Receipt of the CSG was defined as report from the parent/guardian at each visit that at least one member of the household was receiving a CSG from the South African Government. Adolescent depression was a binary variable defined as having a Children's Depression Inventory score of greater than or equal to seven at enrollment [42]. Physical intimate partner violence was a binary variable defined as having ever experienced any physical intimate partner violence (IPV) by a partner at enrollment based on the WHO global questionnaire [5, 43]. High attendance in school was a time-varying variable defined at each visit as attending $\geq 80 \%$ of school days in the months between study visits and was dichotomized as high attendance versus low attendance ( $<80 \%$ school days), based on the condition used to receive cash in the original trial $[5,37]$. The attendance variable was constructed from high school attendance registers from schools where the young women were enrolled. Perception that a parent/guardian cares was a time-varying binary variable constructed based on the question asked at each visit of the young woman "How much do you feel that [parent/guardian] cares for you." Caregiver care was defined as answering that the parent/guardian cares "a lot" or "somewhat" compared to answering "not at all". Receipt of the $\mathrm{CCT}$ intervention was defined as being randomized to the intervention arm of the trial at enrollment. Most measures were adapted from questionnaires that have been used previously in South Africa.

Covariates were selected by drawing a diagram of relationships between joint exposures, confounders, and HIV infection, and each individual exposure-outcome relationship. All confounders were selected based on prior literature indicating the importance of these variables. Confounders included time interval, age at enrollment, time-varying socioeconomic status (SES) (asset quartiles), and timevarying orphan status (one or both parents died when the young woman was $<18$ years). We did not adjust for other grants in the household but did adjust for SES to account for overall household SES.

\section{Statistical Analysis}

We modeled potential interventions on each exposure using the g-formula. The g-formula can be used to model how interventions might hypothetically reduce HIV risk similar to other forms of simulation modeling [44]. First, we estimated the average association between each exposure and HIV incidence by comparing HIV incidence if all girls had an exposure versus if no girls had the exposure. For example, the risk of HIV if all girls were in a household that received a CSG at each visit versus if all girls were in households that did not receive a CSG. Second, we estimated the HIV risk given the observed (real) distribution of each risk factor compared to a population in which all girls had risks removed. For example, the risk of HIV if all girls were in a household that received a CSG at each visit versus if $79.7 \%$ (observed) were in a household that received the CSG. Third, we modeled potential interventions by changing the CSG exposure in combination with reducing other risk factors and receipt of the CCT. We estimated the potential effect of each combination of factors on incident HIV infection compared with the risk of HIV infection that was observed in the data set with the observed (real) distribution of each risk factor. Lastly, we examined combinations stratified by CCT intervention arm. To assess the causal assumption of positivity, we checked the data to ensure that we had individuals exposed and unexposed in all covariate strata for the combinations. Under a set of identifiability assumptions, the associations estimated in this manuscript can be interpreted as causal effects, but we refer to these estimates as "associations" or "potential effects" because of possible violations to these assumptions. More discussion of the possible violations of these assumptions is included in the discussion section.

To implement the g-formula, we (i) parametrically modeled probabilities of the exposures, time-varying confounders and the outcome at each time point, conditional on exposure history and covariates in the observed data [45-52]. We used pooled logistic models for binary variables and linear regression models for continuous variables. We modeled time points until infection or graduation from high school (over grade 12), as this is when AGYW would have exited the trial. We then (ii) drew a Monte Carlo sample of 10,000 participants drawn with replacement from the observed data. 
We (iii) used the conditional probabilities estimated in (i) to predict risk of HIV by time $t$. We then (iv) compared our predicted risk under no intervention on the exposure (i.e., under the "natural course" [44]) with the observed data to assess the fit of the parametric models $[44,45]$. We also compared the natural course (simulated) with the observed data for exposures, and time-varying confounders to make sure that the simulated cohort accurately represented the observed data. Finally, we (v) estimated risk under each intervention scenario by setting the values of factors individually and in combination in the simulated cohort. We computed 95\% CIs by repeating the above steps (i) through (vi) on 500 nonparametric bootstrap resamples of the original data.

We compared risk of HIV at the end of the study period (4 years) under each intervention using risk differences and risk ratios calculated using the complement of the extended Kaplan Meir estimator [45]. Interventions that were assessed included the CSG and all combinations of increasing caregiver care, decreasing low school attendance, decreasing IPV and decreasing adolescent depression. An intervention on the CCT was added to the prior combinations that had the largest reductions in HIV incidence. Two-way interaction terms were included between all potential exposures in the outcome model to estimate joint effects of these exposures. We also assessed interaction between the CSG and each exposure by calculating the interaction contrast (IC). The IC is a measure of whether a joint intervention on two exposures has a greater additive association with incident HIV infection than expected based on the sum of the two individual interventions alone. The IC is 0 when there is no interaction.

\section{Results}

A total of 2328 AGYW were HIV negative at enrollment and had at least one follow-up visit. The simulated cohort closely replicated the characteristics of the observed cohort of 2328 (Table 1). In the observed data over the study period, $75.4 \%$ ( $\mathrm{N}=5028$ person visits) of AGYW lived in a household that had received a CSG (79.7\% at enrolment), $22.1 \%(\mathrm{~N}=1470$ person visits) perceived that their parent/guardian cared a lot or somewhat $(5.9 \%$ a lot, $16.2 \%$ somewhat and $77.9 \%$ not at all), and $94.1 \%(\mathrm{~N}=6398$ person visits $)$ had high

Table 1 Characteristics of young women aged 13 to 20 without prevalent HIV and with at least one follow-up visit in Agincourt, South Africa enrolled in HPTN 068

\begin{tabular}{|c|c|c|c|c|}
\hline & $\begin{array}{l}\text { Enrollment } \\
\text { observed } \\
(\mathrm{N}=2328) \\
\mathrm{N}(\%)\end{array}$ & $\begin{array}{l}\text { All visits } \\
(\mathrm{N}=6796) \\
\mathrm{N}(\%)\end{array}$ & $\begin{array}{l}\text { Enrollment Simu- } \\
\text { lated }(\mathrm{N}=10,000) \\
\mathrm{N}(\%)\end{array}$ & $\begin{array}{l}\text { All visits } \\
\text { simulated }(\mathrm{N}=37,240) \\
\mathrm{N}(\%)\end{array}$ \\
\hline \multicolumn{5}{|l|}{ Young women's age at baseline (year) } \\
\hline Age 13-14 & $734(31.53)$ & $2524(37.19)$ & $3144(31.43)$ & $12,388(33.27)$ \\
\hline Age $15-16$ & $996(42.78)$ & $2947(43.43)$ & $4334(43.34)$ & $16,402(44.04)$ \\
\hline Age $17-18$ & $498(21.39)$ & $1105(16.28)$ & $2044(20.44)$ & $6864(18.43)$ \\
\hline Age $18-20$ & $100(4.3)$ & $210(3.09)$ & $478(4.78)$ & $1586(4.26)$ \\
\hline \multicolumn{5}{|l|}{ Household wealth } \\
\hline Low & $587(25.26)$ & $1298(19.29)$ & $2497(25.02)$ & $7194(19.33)$ \\
\hline Middle to low & $620(26.68)$ & $1807(26.85)$ & $2707(27.12)$ & $9753(26.20)$ \\
\hline Middle & $569(24.48)$ & $1898(28.20)$ & $2465(24.69)$ & $10,414(27.98)$ \\
\hline High & $548(23.58)$ & $1727(25.66)$ & $2313(23.17)$ & $9861(26.49)$ \\
\hline CCT randomization arm & $1214(52.15)$ & $3542(52.20)$ & $5251(52.51)$ & $19,556(52.51)$ \\
\hline Double or single orphan & $100(4.35)$ & $371(5.50)$ & $462(4.68)$ & $1708(4.64)$ \\
\hline Feels close to parent & $1917(82.84)$ & $5506(82.78)$ & $8255(83.01)$ & $30,715(82.94)$ \\
\hline Perception that parent/guardian cares a lot or somewhat & $510(22.02)$ & $1470(22.10)$ & $2264(22.73)$ & $8617(23.37)$ \\
\hline Household receiving any grants & $2055(88.27)$ & $5727(85.58)$ & $8780(87.80)$ & $32,766(87.99)$ \\
\hline Receiving CSG for at least one child in household & $1856(79.73)$ & $5028(75.43)$ & $7964(79.64)$ & $28,107(75.48)$ \\
\hline Ever experienced any physical IPV & $391(17.15)$ & $1051(15.82)$ & $1696(17.29)$ & $6171(16.91)$ \\
\hline High attendance in school ( $\geq 80 \%$ school days) & $2255(95.99)$ & $6398(94.09)$ & $9552(95.92)$ & $34,338(93.15)$ \\
\hline Children's depression inventory score $\geq 7$ & $410(18.53)$ & $1176(18.21)$ & $1828(19.21)$ & $6679(18.87)$ \\
\hline
\end{tabular}

Missing data in observed at enrollment: asset $\mathrm{N}=4$; parent close $\mathrm{N}=14$; parent cares $\mathrm{N}=12$; HSV 3; orphan 27; pregnant 28; death $\mathrm{N}=1$; CSG N=273; depression 115; IPV 48; school attendance 10; Missing in observed over all visits; close parent =135; care parent N=133; assets $\mathrm{N}=56$; orphan $\mathrm{N}=37$; HSV $\mathrm{N}=7$; pregnant $\mathrm{N}=181$; death $\mathrm{N}=95$; receiving any grant including CSG $\mathrm{N}=94$; CSG $\mathrm{N}=94$; depression 329 ; IPV N =58; high school attendance $\mathrm{N}=18$ 
attendance in school. At enrollment, $17.1 \%(\mathrm{~N}=391)$ had ever experienced physical IPV, and $18.5 \%(\mathrm{~N}=410)$ were depressed. Simulated HIV risk over the study period (5.4\%) closely matched the observed data (5.8\%) (Table 1; Appendix Fig. 2).

Table 2 shows the potential effects of each individual exposure alone on HIV incidence. At 4 years, the risk of HIV if all AGYW received a CSG at each visit was $4.9 \%$ compared to $8.4 \%$ if no one received a CSG for a risk difference (RD) of $-3.5 \%$ (95\% Confidence Interval (CI) $-8.1 \%$, $1.2 \%$ (Table 2)). The risk of HIV if all AGYW received the
$\mathrm{CCT}$ at enrollment was $-2.1 \%$ compared to none receiving the CCT $(95 \%$ CI $-7.3 \%, 3.1 \%)$. Next, we compared the risk of HIV given the observed distribution of each risk factor to the risk of HIV if all girls had their risk removed (Table 2). All reductions in HIV incidence under this comparison were smaller and were less than $1 \%$. However, given the $5.6 \%$ incidence in this study a $-0.9 \%$ reduction as was seen with caregiver care still corresponds with a $16 \%$ relative reduction in HIV incidence $(0.9 / 5.6=16 \%)$.

Table 3 shows the potential effects of reducing exposure to each risk factor paired with receipt of a CSG. Reducing

Table 2 The modeled exposure effect and population attributable effect of intervening on each individual exposure on incident HIV infection among South African AGYW enrolled in HPTN 068

\begin{tabular}{|c|c|c|c|c|c|c|}
\hline & $\begin{array}{l}\text { Child support } \\
\text { grant* }\end{array}$ & Caregiver care* & $\begin{array}{l}\text { No depression at } \\
\text { enrollment }\end{array}$ & $\begin{array}{l}\text { Never IPV at } \\
\text { enrollment }\end{array}$ & $\begin{array}{l}\text { High school attend- } \\
\text { ance* }\end{array}$ & CCT intervention \\
\hline \multicolumn{7}{|c|}{ All exposed versus all unexposed } \\
\hline $\begin{array}{l}\text { Risk all unex- } \\
\text { posed }(\%, \\
95 \% \mathrm{CI})\end{array}$ & $8.4(5.3,11.6)$ & $6.8(4.6,9.0)$ & $10.3(6.2,14.4)$ & $6.2(2.7,9.7)$ & $14.6(8.1,21.1)$ & $7.2(4.8,9.6)$ \\
\hline $\begin{array}{l}\text { Risk all exposed } \\
(\%, 95 \% \mathrm{CI})\end{array}$ & $4.9(2.3,7.7)$ & $4.6(2.2,7.0)$ & $5.2(3.4,7.1)$ & $6.1(6.2,8.0)$ & $5.1(3.1,7.1)$ & $5.1(1.2,9.0)$ \\
\hline $\mathrm{RD}(\%)$ & $-3.5(-8.1,1.2)$ & $-2.2(-4.8,0.4)$ & $\begin{array}{l}-5.1(-8.7,- \\
1.5)\end{array}$ & $-0.1(-3.1,2.9)$ & $\begin{array}{c}-9.5(-16.0,- \\
2.9)\end{array}$ & $-2.1(-7.3,3.1)$ \\
\hline $\mathrm{RR}$ & $0.59(0.27,1.27)$ & $0.68(0.41,1.13)$ & $0.51(0.32,0.81)$ & $0.98(0.60,1.61)$ & $0.35(0.19,0.65)$ & $0.71(0.26,1.94)$ \\
\hline \multicolumn{7}{|c|}{ All exposed versus observed } \\
\hline $\begin{array}{l}\text { Risk under } \\
\text { observed (\%, } \\
95 \% \mathrm{CI})\end{array}$ & $5.6(3.5,7.6)$ & $5.6(3.5,7.6)$ & $5.6(3.5,7.6)$ & $5.6(3.5,7.6)$ & $5.6(3.5,7.6)$ & $5.6(3.5,7.6)$ \\
\hline $\begin{array}{l}\text { Risk all exposed } \\
(\%, 95 \% \mathrm{CI})\end{array}$ & $5.0(2.3,7.7)$ & $4.6(2.2,7.0)$ & $5.2(3.4,7.1)$ & $6.1(4.2,8.0)$ & $5.1(3.1,7.1)$ & $5.1(1.2,9.0)$ \\
\hline $\mathrm{RD}(\%)$ & $-0.6(-1.9,0.8)$ & $-0.9(-2.9,1.1)$ & $-0.3(-1.3,0.7)$ & $0.5(-0.3,1.4)$ & $-0.4(-1.2,0.4)$ & $-0.4(-1.2,0.4)$ \\
\hline RR & $0.90(0.67,1.20)$ & $0.68(0.41,1.13)$ & $0.95(0.78,1.15)$ & $1.09(0.93,1.28)$ & $0.92(0.78,1.09)$ & $0.92(0.51,1.66)$ \\
\hline
\end{tabular}

Bold if confidence intervals for risk differences do not cross null value of 0 and for risk ratios do not cross null value of 1

*Time-varying; measured as each visit

Table 3 Risk ratios (RR), risk differences (RD; \%) and 95\% confidence intervals $(\mathrm{CI})$ for the potential effect of various interventions on receipt of a child support grant (CSG) at each visit paired with caregiver care at each visit, eliminating adolescent depression at enrollment, eliminating IPV at enrollment, high attendance in school at each visit, or receipt of the CCT intervention at enrollment on incident HIV infection at 4 years of follow up among South Africa AGYW enrolled in HPTN 068

\begin{tabular}{|c|c|c|c|c|c|}
\hline & $\begin{array}{l}\text { CSG plus } \\
\text { Caregiver care }\end{array}$ & $\begin{array}{l}\text { CSG plus } \\
\text { No depression }\end{array}$ & $\begin{array}{l}\text { CSG plus } \\
\text { No IPV }\end{array}$ & $\begin{array}{l}\text { CSG plus } \\
\text { High school attendance }\end{array}$ & $\begin{array}{l}\text { CSG plus } \\
\text { CCT }\end{array}$ \\
\hline \multicolumn{6}{|l|}{ Total effect } \\
\hline Risk under observed $(\%, 95 \% \mathrm{CI})$ & $5.6(3.5,7.6)$ & $5.6(3.5,7.6)$ & $5.6(3.5,7.6)$ & $5.6(3.5,7.6)$ & $5.6(3.5,7.6)$ \\
\hline $\begin{array}{l}\text { Risk under all exposed (\%, } \\
95 \% \mathrm{CI})\end{array}$ & $2.9(0.2,5.6)$ & $3.8(1.5,6.1)$ & $4.5(1.9,7.2)$ & $4.2(1.6,6.9)$ & $3.9(-0.9,8.7)$ \\
\hline $\mathrm{RD}(\%)$ & $-2.6(-4.7,-0.6)$ & $-1.7(-3.0,-0.4)$ & $-1.0(-2.4,0.4)$ & $-1.3(-2.7,0.1)$ & $-1.7(-5.1,1.8)$ \\
\hline RR & $0.52(0.29,0.96)$ & $0.69(0.49,0.97)$ & $0.82(0.59,1.14)$ & $0.76(0.55,1.07)$ & $0.70(0.2,2.1)$ \\
\hline Interaction contrast $(\mathrm{IC})^{*}$ & $-5.25 \%$ & $-0.32 \%$ & $0.19 \%$ & $6.85 \%$ & $-1.67 \%$ \\
\hline
\end{tabular}

Bold if confidence intervals for risk differences do not cross null value of 0 and for risk ratios do not cross null value of 1

$* I C<0$ indicates a net increase in the inverse effect with joint exposure (synergism; IC $>0$ indicates a net reduction in the inverse effects with joint exposure (antagonism). $\mathrm{IC}=0$ if $\mathrm{R}_{11}-\mathrm{R}_{00}=\left(\mathrm{R}_{10}-\mathrm{R}_{00}\right)+\left(\mathrm{R}_{01}-\mathrm{R}_{00}\right)[60] 1$ 
exposure to each risk factor in combination with the CSG showed a greater reduction in HIV risk than reducing exposure to each risk factor alone. Receipt of a CSG plus caregiver care had the largest association with incident HIV infection when combining the CSG with a single intervention. At 4 years, the observed risk of HIV was $5.6 \%$ compared to $2.9 \%$ if all AGYW received a CSG at each visit and had caregiver care at each visit for a risk difference of $-2.6 \%$ (95\% CI $-4.7 \%,-0.6 \%)$. We found an interaction between the CSG and caregiver care (interaction contrast (IC) $-5.6 \%$ ) indicating that the protective association with HIV became stronger with joint exposure. We did not find an additive interaction of the CSG with IPV or adolescent depression but did find a small interaction ( $\mathrm{IC}=-1.7 \%$ ) with exposure to the CCT. For school attendance, we found that exposure to school attendance and the CSG actually had less of a protective relationship with HIV compared to what we would expect with each factor alone (IC was positive, $6.9 \%$ ). This may be because each one is so strongly protective, and/or the two factors operate on a similar pathway, such that adding one to the other does not provide much additional protection.

Table 4 examines all combinations of interventions on risk factors plus receipt of a CSG. The combinations that included receipt of the CSG and caregiver care had the largest association with incident HIV (Interventions 1-4 and 8-12). Intervention 1 to provide a CSG at each visit, increase caregiver care at each visit, eliminate adolescent depression at enrollment, eliminate IPV at enrollment, and increase school attendance at each visit had the largest reduction in risk of $\mathrm{HIV}$ at 4 years (RD $-3.4 \%$; $95 \% \mathrm{CI}-5.5,-1.4$ ). Intervention 2 showed a similar reduction in HIV risk at 4 years as intervention 1 and did not require an intervention on school attendance or IPV (RD - 3.0\%; (95\% CI - 5.1, - 0.9). Interventions $8-12$ with the addition of the CCT showed similar reductions in HIV incidence to interventions 1-4 without the CCT. Figure 1 shows the interventions with the largest potential effects on HIV incidence from Table 4, stratified by receipt of the CCT. There were no substantial differences in the associations of any potential interventions with HIV when stratified by receipt of the conditional cash transfer intervention (Fig. 1).

\section{Discussion}

Our analysis demonstrates that combining a government cash transfer program with other interventions to address psychosocial factors may substantially improve the impact of such a program on HIV incidence. Neither the CSG nor the CCT intervention were independently associated with HIV incidence. When examining the impact of the CSG paired with intervening on other risk factors, receipt of the CSG plus caregiver care showed by far the largest decrease in incident HIV infection. The relationship of the CSG plus parental care on HIV incidence was further improved by
Table 4 Risk differences (RD; \%) and 95\% confidence intervals (CI) for the potential effect of various interventions on a combination of receipt of a child support grant (CSG) at each visit, caregiver care at each visit, eliminating adolescent depression at baseline, eliminating
IPV at baseline, high attendance in school at each visit and receipt of CCT intervention at enrollment on incident HIV infection at 4 years of follow up among South Africa AGYW enrolled in HPTN 068

Intervention

\begin{tabular}{|c|c|c|}
\hline $\begin{array}{l}\text { Risk under } \\
\text { all exposed } \\
(95 \% \mathrm{CI})\end{array}$ & $\begin{array}{l}\text { Risk under observed } \\
(95 \% \mathrm{CI})\end{array}$ & $\begin{array}{l}\text { Risk difference }(95 \% \\
\text { CI)* }\end{array}$ \\
\hline $2.1(-0.2,4.4)$ & $5.6(3.5,7.6)$ & $-3.4(-5.5,-1.4)$ \\
\hline $2.5(0.1,5.0)$ & $5.6(3.5,7.6)$ & $-3.0(-5.1,-0.9)$ \\
\hline $3.2(0.5,6.0)$ & $5.6(3.5,7.6)$ & $-2.3(-4.5,-0.2)$ \\
\hline $3.4(0.6,6.1)$ & $5.6(3.5,7.6)$ & $-2.2(-4.4,0.0)$ \\
\hline $3.5(1.2,5.8)$ & $5.6(3.5,7.6)$ & $-2.0(-3.4,-0.7)$ \\
\hline $3.6(1.3,6.0)$ & $5.6(3.5,7.6)$ & $-1.9(-3.3,-0.5)$ \\
\hline $4.0(1.5,6.4)$ & $5.6(3.5,7.6)$ & $-1.6(-2.9,-0.2)$ \\
\hline $1.7(-1.5,4.9)$ & $5.6(3.5,7.6)$ & $-3.9(-6.3,-1.5)$ \\
\hline $2.2(-1.8,6.2)$ & $5.6(3.5,7.6)$ & $-3.4(-6.4,-0.4)$ \\
\hline $1.9(-1.5,5.3)$ & $5.6(3.5,7.6)$ & $-3.6(-6.2,-1.1)$ \\
\hline $2.6(-1.4,6.6)$ & $5.6(3.5,7.6)$ & $-2.9(-5.9,0.1)$ \\
\hline $2.9(-1.2,7.1)$ & $5.6(3.5,7.6)$ & $-2.6(-5.7,0.4)$ \\
\hline
\end{tabular}

(1) CSG, increase caregiver care, eliminate adolescent depression, eliminate IPV, and increase school attendance

(2) CSG, eliminate adolescent depression and increase caregiver care

(3) CSG, increase caregiver care and increase school attendance

(4) CSG, eliminate IPV and increase caregiver care

(5) CSG, eliminate adolescent depression, and increase school attendance

(6) CSG, eliminate adolescent depression and eliminate IPV

(7) CSG, eliminate IPV, and increase school attendance

Interventions from above plus CCT intervention

(8) CCT, CSG, increase caregiver care, eliminate adolescent depression, eliminate IPV, and increase school attendance

(9) CCT, CSG, increase caregiver care and increase school attendance

(10) CCT, CSG, eliminate adolescent depression and increase caregiver care

(11) CCT, CSG, eliminate IPV and increase caregiver care

(12) CCT, CSG and increase caregiver care

*Bold if confidence intervals for risk differences do not cross null value of 0 


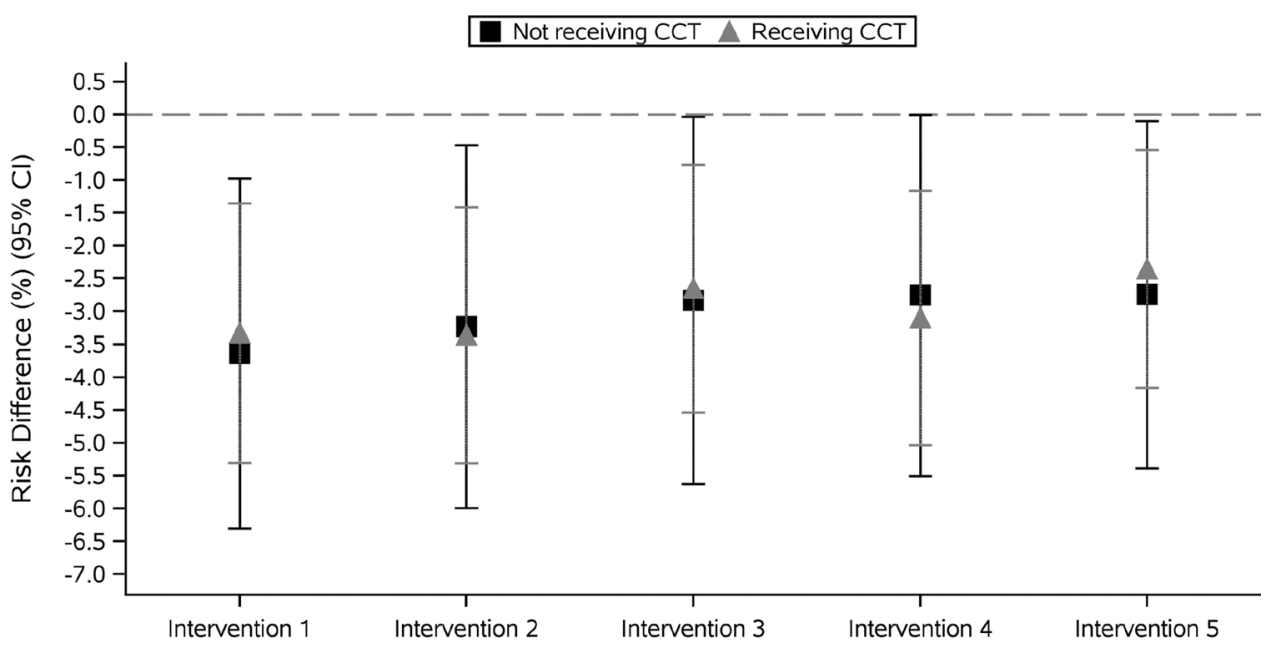

Fig. 1 Risk differences (RD; \%) and 95\% confidence intervals (CI) for the potential effect of various interventions on a combination of receipt of a child support grant (CSG) at each visit, increasing caregiver care at each visit, eliminating adolescent depression at enrollment, eliminating IPV at enrollment and high attendance in school at each visit on incident HIV infection at 4 years of follow up, stratified by receipt of conditional cash transfer (CCT) intervention. Interven-

reducing exposure to all other risk factors. A potential intervention to provide a CSG, decrease adolescent depression, and increase caregiver care had the largest reduction in HIV incidence with changes in the fewest number of risk factors. Reductions in HIV incidence were not substantially increased by adding receipt of the CCT intervention or modified by the CCT intervention. Therefore, receipt of the CCT may not have provided additional benefit over the CSG alone or in combination with other interventions.

Our findings support the rationale for cash interventions in tandem with other interventions to increase psychosocial support. Prior work by Cluver et al. found that receipt of the South African CSG plus caregiver care or other psychosocial interventions results in a larger reduction in sexual risk behaviors than receipt of cash alone [14, 15]; our results support these findings and add to them by showing potential effects on HIV incidence. We find that the protective association of the CSG was stronger with joint exposure to caregiver care, and combinations including these two factors were associated with the largest reductions in HIV incidence compared to other combinations examined. Combination interventions may have an added impact on HIV because they address multiple mechanisms of risk, multilevel and intersecting social factors and reduce cumulative experiences of adversity [24]. Prior findings also suggest that social protection may act as the 'glue' for cash programs to have positive effects, or vice versa, that combined interventions bolster social pathways associated with improved resilience and that they may facilitate access to services for vulnerable populations $[14,15]$. Therefore, cash plus care tion 1 Provide CSG, increase caregiver care, eliminate adolescent depression, eliminate IPV, and increase school attendance. Intervention 2 Provide CSG, eliminate adolescent depression and increase caregiver care; Intervention 3 Provide CSG, eliminate IPV and increase caregiver care; Intervention 4 Provide CSG, increase caregiver care and increase school attendance. Intervention 5 Intervention to provide CSG and increase caregiver care

interventions in our study may have had more of an association over cash alone because of increases in social support that improve mental health or facilitate access to cash, health services, or other resources like school that protect against HIV. We add to prior evidence by demonstrating that cash plus care can impact HIV incidence and by examining the combined effect of intervening on multiple structural and behavioral factors simultaneously. Additionally, while we know that combined strategies for HIV prevention can be effective, these programs are often very large and resource intensive. Our analysis helps to identify which specific interventions could be combined to reduce the most infections from a large list of possible combinations.

Caregiver care emerged as the most important factor to reduce HIV incidence in AGYW in combination with the CSG. Caregiver care in combination with the CSG showed larger reductions in HIV incidence than receipt of the CSG alone. This greater reduction in risk may reflect the fact that government grants are given at the household level and therefore may benefit young women more in households where they have a supportive parent/caregiver who includes the needs of the AGYW in household decision-making. There may also be other mechanisms through which the combined effects of cash plus care operate such as improved mental health, social support, and overall well-being of the child. Adolescent depression emerged as another key factor for intervention to reduce HIV incidence. A recent systematic review of mental health interventions found that universally delivered interventions can improve adolescent mental health and reduce risk behavior, particularly those 
that include interpersonal skills training, emotional regulation, and alcohol and drug education [53].

While the percentage of AGYW that reported they had a parent/caregiver that cared a lot or somewhat was low (less than a quarter), we found it to be highly associated with lower risk of HIV infection. This evidence highlights the importance of strengthening caregiver-child relationships to prevent HIV among AGYW. Family based HIV-prevention programs have increased safer sexual behaviors and improved adherence and other behaviors in HIV positive youth [54-56]. Yet, research is still needed to fully understand how families can be supported and encouraged to promote healthy behaviors in young women and reduce risk of HIV [57].

There are several limitations to our analysis. First, the $\mathrm{g}$-formula relies on the assumptions of correctly specified models and no unmeasured confounding [44]. We saw that our simulated cohort was similar to the observed data in HIV risk and other characteristics, suggesting that the models were adequately specified. We also assumed causal consistency (that any differences between individuals in mechanism of exposure assignment are ignorable), positivity (we have individuals exposed and unexposed in all covariate strata) and that the exposure precedes the outcome (we used HIV infections that occurred at the next time point after exposure to ensure temporality). We ensured that the assumption of temporality and positivity were met through sensitivity analyses, however, it is possible that participants may have interpreted the question about caregiver care differently, therefore violating our assumption of consistency.

Additionally, our analysis relies on self-reported information and sexual behaviors that may be misreported due to social desirability bias and our data come from a randomized controlled trial of a CCT intervention. Prior analyses of this data have shown that there was selection bias and a Hawthorne effect where girls in the study were more likely to be enrolled in school and stay in school than the underlying population in the study area [58]. However, if the prevalence of school dropout were higher, as we would expect in the larger underlying population, then changes in school attendance and other related characteristics would have more of an effect because reductions in prevalence would be larger [59].

In conclusion, addressing social determinants such as poverty through the use of cash transfer programs can have an impact on HIV incidence in AGYW when combined with other social and behavioral factors such as caregiver care and mental health services. Our results support the need for cash plus other structural and psychosocial programs. Household cash transfers could be combined with interventions to improve caregiver care and reduce adolescent depression to more effectively reduce HIV incidence among adolescent girls and young women.

\section{Appendix}

See Fig. 2.

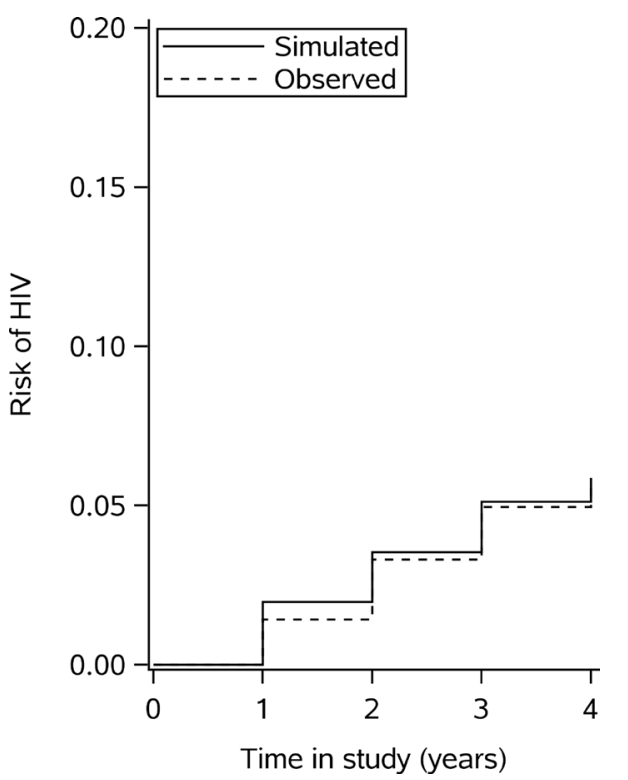

Fig. 2 Observed versus simulated cumulative incidence of HIV by time since study enrollment

Acknowledgements We would like to thank the HPTN 068 participants and study team.

Author Contributions MCDS, DW, JKE, KK and AP contributed to the conception, design of the analysis and writing of the paper. DW, JE and JA provided statistical support on the analysis. The remaining authors were involved in data acquisition, data collection, study management and design of the original parent study. All authors have reviewed the paper, provided comments and edits to the manuscript and have read and approved the final manuscript.

Funding This study was funded by the National Institutes of Health (R01 MH110186, R01MH087118) and by Award Numbers UM1 AI068619 (HPTN Leadership and Operations Center), UM1AI068617 (HPTN Statistical and Data Management Center), and UM1AI068613 (HPTN Laboratory Center) from the National Institute of Allergy and Infectious Diseases, the National Institute of Mental Health and the National Institute on Drug Abuse of the National Institutes of Health. This work was also supported by the Carolina Population Center and its NIH Center Grant (P2C HD050924) and NIH K01AI125087. The content is solely the responsibility of the authors and does not necessarily represent the official views of the National Institutes of Health. The MRC/Wits Rural Public Health and Health Transitions Research Unit and Agincourt Health and Socio-Demographic Surveillance System have been supported by the University of the Witwatersrand, the Medical Research Council, South Africa, and the Wellcome Trust, UK (Grants 058893/Z/99/A; 069683/Z/02/Z; 085477/Z/08/Z; $085477 / \mathrm{B} / 08 / \mathrm{Z}$ ). Funding was also received through internal funding from RTI international. 
Availability of Data and Materials Data from the HPTN 068 study are currently available through the HIV Prevention Trials Network.

Code Availability Code for this project is available by contacting the corresponding author.

\section{Compliance with Ethical Standards}

Conflict of interest We declare no competing interests.

Ethical Approval Institutional review board approval was obtained from the University of North Carolina at Chapel Hill and the University of the Witwatersrand Human Research Ethics Committee as well as the Provincial Department of Health's Research Ethics Committee.

Informed Consent Each young woman and her parent or guardian provided written informed consent. Written assent was obtained for young women younger than 18 years. Consent and assent forms were available in English and Shangaan.

Open Access This article is licensed under a Creative Commons Attribution 4.0 International License, which permits use, sharing, adaptation, distribution and reproduction in any medium or format, as long as you give appropriate credit to the original author(s) and the source, provide a link to the Creative Commons licence, and indicate if changes were made. The images or other third party material in this article are included in the article's Creative Commons licence, unless indicated otherwise in a credit line to the material. If material is not included in the article's Creative Commons licence and your intended use is not permitted by statutory regulation or exceeds the permitted use, you will need to obtain permission directly from the copyright holder. To view a copy of this licence, visit http://creativecommons.org/licenses/by/4.0/.

\section{References}

1. Bastagli F, Hagen-Zanker J, Harman L, Barca V, Sturge G, Schmidt T, et al. Cash transfers: what does the evidence say? A rigorous review of impacts and the role of design and implementation features. London: Overseas Development Institute. 2016; Available from: https://www.odi.org/publications/10505cash-transfers-what-does-evidence-say-rigorous-review-impactsand-role-design-and-implementation\#: :text $=$ This $\% 20$ rigorous $\%$ 20review $\% 20$ of $\% 20$ the, of $\% 20$ its $\% 20$ kind $\% 20$ to $\% 20$ date.\&text $=$ The\%20review\%20covers\%20the\%20intended,Education

2. Heise L, Lutz B, Ranganathan M, Watts C. Cash transfers for HIV prevention: considering their potential. J Int AIDS Soc. 2013;16:18615.

3. Pettifor A, MacPhail C, Nguyen N, Rosenberg M. Can money prevent the spread of HIV? A review of cash payments for HIV prevention. AIDS Behav. 2012;16:1729-38.

4. Baird SJ, Garfein RS, McIntosh CT, Özler B. Effect of a cash transfer programme for schooling on prevalence of HIV and herpes simplex type 2 in Malawi: a cluster randomised trial. Lancet. 2012;379:1320-9.

5. Pettifor A, MacPhail C, Hughes JP, Selin A, Wang J, GómezOlivé FX, et al. The effect of a conditional cash transfer on HIV incidence in young women in rural South Africa (HPTN 068): a phase 3, randomised controlled trial. Lancet Glob Health [Internet]. 2016; Available from: http://linkinghub.elsevier.com/retri eve/pii/S2214109X16302534.
6. Karim QA. Impact of conditional cash incentives on HSV-2 and HIV in rural high school students in South Africa. In: 8th IAS Conference HIV Pathogonesis, Treatment and Prevention. Vancouver, Canada; 2015

7. Görgens M, Mabuza K, De Walque D. Sitakhela Likusasa impact evaluation: financial incentives to reduce HIV incidence among adolescent girls and young women (AGYW) in Eswatini. In: 10th IAS Conference on HIV Science. Mexico City, Mexico; 2019.

8. Handa S, Halpern CT, Pettifor A, Thirumurthy H. The government of Kenya's cash transfer program reduces the risk of sexual debut among young people age 15-25. PLoS ONE. 2014;9:e85473.

9. Siaplay M. The impact of social cash transfers on young adults' labor force participation, schooling, and sexual behaviors in South Africa. Oklahoma State University; 2012.

10. Heinrich CJ, Hoddinott J, Samson M. Reducing adolescent risky behaviors in a high-risk context: the effects of unconditional cash transfers in South Africa. Econ Dev Cult Change. 2017;65:619-52.

11. Team ZHSCTE. Zimbabwe's harmonised social cash transfer programme endline impact evaluation report. 2018.

12. Abdoulayi UNCS, Angeles G, Barrington C, Brugh K, Handa S, Molotsky A, et al. Malawi social cash transfer programme endline impact evaluation report [Internet]. 2016. Available from: https://transfer.cpc.unc.edu/tools/reports/malawi-reports/.

13. Department of Social Development, SASSA, UNICEF. The South African Child Support Grant Impact Assessment [Internet]. Evidence from a survey of children adolescents their households. Pretoria; 2012. Available from: http://www.unicef. org/southafrica/SAF_resources_csg2012s.pdf.

14. Cluver LD, Orkin FM, Boyes ME, Sherr L. Cash plus care: social protection cumulatively mitigates HIV-risk behaviour among adolescents in South Africa. AIDS. 2014;28:S389-97.

15. Toska E, Cluver LD, Boyes ME, Isaacsohn M, Hodes R, Sherr L. School, supervision and adolescent-sensitive clinic care: combination social protection and reduced unprotected sex among HIV-positive adolescents in South Africa. AIDS Behav. 2017;21:2746-59.

16. Birdthistle I, Schaffnit SB, Kwaro D, Shahmanesh M, Ziraba A, Kabiru CW, et al. Evaluating the impact of the DREAMS partnership to reduce HIV incidence among adolescent girls and young women in four settings: a study protocol. BMC Public Health. 2018;1:912.

17. Clark S, Paul M, Aryeetey R, Marquis G. An assets-based approach to promoting girls' financial literacy, savings, and education. J Adolesc. 2018;68:94-104.

18. Rosenberg NE, Pettifor AE, Myers L, Phanga T, Marcus R, Bhushan NL, et al. Comparing four service delivery models for adolescent girls and young women through the Girl Power' study: protocol for a multisite quasi-experimental cohort study. BMJ Open. 2017;7:e018480.

19. Ssewamala FM, Bermudez LG, Neilands TB, Mellins CA, McKay MM, Garfinkel I, et al. Suubi4Her: a study protocol to examine the impact and cost associated with a combination intervention to prevent HIV risk behavior and improve mental health functioning among adolescent girls in Uganda. BMC Public Health. 2018;18:693.

20. Kajula L, Gilbert U, Palermo T. CashPlus: adolescent health, livelihood and well-being intervention as part of Tanzania's productive social safety network. AIDS Research and Human Retroviruese. Vol. 34. 140 Huguenot Stress, 3RD FL, New Rochelle, NY 10801 USA: Mary Ann Liebert, INC, 2018

21. Zulaika G, Kwaro D, Nyothach E, Wang D, Zielinski-Gutierrez E, Mason L, et al. Menstrual cups and cash transfer to reduce sexual and reproductive harm and school dropout in adolescent schoolgirls: study protocol of a cluster-randomised controlled trial in western Kenya. BMC Public Health. 2019;19:1317. https://doi.org/10.1186/s12889-019-7594-3. 
22. Austrian K, Soler-Hampejsek E, Mumah J, Kangwana B, Wado Y, Abuya B, et al. Adolescent girls initiative-Kenya: midline results report. Nairobi, Kenya; 2018.

23. Human Sciences Reserch Council. Evaluating an incentivised behaviour change intervention for young women, aged 19-24 years in King Cetshwayo District, KwaZulu-Natal; 2018.

24. Cluver LD, Orkin FM, Yakubovich AR, Sherr L. Combination social protection for reducing HIV-risk behavior among adolescents in South Africa. J Acquir Immune Defic Syndr. 2016;72:96-104.

25. UNAIDS. Fast-tracking combination prevention: towards reducing new HIV infections to fewer than 500,000 by 2020 [Internet]. Geneva; 2015. Available from: http://www.unaids.org/en/ resources/documents/2015/20151019_JC2766_Fast_tracking_ combination_prevention\% $\%$ A $\% 0 \mathrm{~A}$.

26. Pettifor A, Nguyen NL, Celum C, Cowan FM, Go V, Hightow-Weidman L. Tailored combination prevention packages and PrEP for young key populations. J Int AIDS Soc. 2015;18(2 Suppl 1):19434. https://doi.org/10.7448/IAS.18.2.19434

27. Pettifor A, Stoner M, Pike C, Bekker L-G. Adolescent lives matter: preventing HIV in adolescents. Curr Opin HIV AIDS. 2018;13:265.

28. Hardee K, Gay J, Croce-Galis M, Afari-Dwamena NA. What HIV programs work for adolescent girls? J Acquir Immune Defic Syndr. 2014;66(Suppl 2):S176-85.

29. Whittle HJ, Palar K, Napoles T, Hufstedler LL, Ching I, Hecht FM, et al. Experiences with food insecurity and risky sex among lowincome people living with HIV/AIDS in a resource-rich setting. $\mathrm{J}$ Int AIDS Soc. 2015;18(1):20293.

30. Stoebenau AK, Wamoyi J. Transactional sex and HIV risk. London; 2018. Accessed from: http://strive.1shtm.ac.uk/system/files/attac hments/STRIVE\%20Transactional\%20Sex\%20Technical\%20Bri ef.pdf

31. Ranganathan M, MacPhail C, Pettifor A, Kahn K, Khoza N, Twine $\mathrm{R}$, et al. Young women's perceptions of transactional sex and sexual agency: a qualitative study in the context of rural South Africa. BMC Public Health. 2017;17:666.

32. Jewkes R, Dunkle K, Nduna M, Shai NJ. Transactional sex and HIV incidence in a cohort of young women in the stepping stones trial. $\mathrm{J}$ AIDS Clin Res. 2012;3:7.

33. Stoner MCD, Nguyen N, Kilburn K, Gomez-Olive FX, Edwards JK, Selin A, et al. Age-disparate partnerships and incident HIV infection in adolescent girls and young women in rural South Africa: an HPTN 068 analysis. AIDS. 2018. https://doi.org/10.1097/QAD. 0000000000002037.

34. Seth P, DiClemente RJ, Lovvorn AE. State of the evidence: intimate partner violence and HIV/STI risk among adolescents. Curr HIV Res. 2013;11:528-35.

35. Pettifor AE, Measham DM, Rees HV, Padian NS. Sexual power and HIV risk, South Africa. Emerg Infect Dis. 2004;10:1996-2004.

36. Hillis SD, Anda RF, Felitti VJ, Nordenberg D, Marchbanks PA. Adverse childhood experiences and sexually transmitted diseases in men and women: a retrospective study. Pediatrics. 2000. https:// doi.org/10.1542/peds.106.1.e11.

37. Stoner MCD, Pettifor A, Edwards JK, Aiello AE, Halpern CT, Julien A, et al. The effect of school attendance and school dropout on incident HIV and HSV-2 among young women in rural South Africa enrolled in HPTN 068. AIDS. 2017;31:2127.

38. Delong S, Pettifor A, Dunkle K, Maman S, Pence B, Powers K. Intimate partner violence and incident HIV among adolescent girls and young women in Agincourt, South Africa. University of North Carolina at Chapel Hill; 2018.

39. Goin DE, Pearson RM, Craske MG, Stein A, Pettifor A, Lippman SA, et al. Depression and incident HIV in adolescent girls and young women in HIV prevention trials network 068: targets for prevention and mediating factors. Am J Epidemiol. 2020;189:422-32.
40. Pettifor A, MacPhail C, Selin A, Gómez-Olivé FX, Rosenberg M, Wagner RG, et al. HPTN 068: a randomized control trial of a conditional cash transfer to reduce HIV infection in young women in South Africa-study design and baseline results. AIDS Behav. 2016;20:1863-82.

41. Kahn K, Collinson MA, Xavier Gómez-olivé F, Mokoena O, Twine $\mathrm{R}$, Mee P, et al. Profile: Agincourt health and socio-demographic surveillance system. Int J Epidemiol. 2012;41:988-1001.

42. Cluver L, Gardner F, Operario D. Psychological distress amongst AIDS-orphaned children in urban South Africa. J Child Psychol Psychiatry. 2007;48:755-63.

43. Kilburn KN, Pettifor A, Edwards JK, Selin A, Twine R, MacPhail $\mathrm{C}$, et al. Conditional cash transfers and the reduction in partner violence for young women: an investigation of causal pathways using evidence from a randomized experiment in South Africa (HPTN 068): an. J Int AIDS Soc. 2018. https://doi.org/10.1002/jia2.25043.

44. Westreich D, Cole SR, Young JG, Palella F, Tien PC, Kingsley $\mathrm{L}$, et al. The parametric g-formula to estimate the effect of highly active antiretroviral therapy on incident AIDS or death. Stat Med. 2012:31:2000-9.

45. Edwards JK, McGrath LJ, Buckley JP, Schubauer-Berigan MK, Cole SR, Richardson DB. Occupational radon exposure and lung cancer mortality: estimating intervention effects using the parametric g-formula. Epidemiology. 2014;25:829-34.

46. Naimi A, Cole S, Hudgens M, Richardson D. Estimating the effect of cumulative occupational asbestos exposure on time to lung cancer mortality: using structural nested failure-time models to account for healthy-worker survivor bias. Epidemiology. 2014;25:246-54.

47. Taubman SL, Robins JM, Mittleman MA, Hernán MA. Intervening on risk factors for coronary heart disease: an application of the parametric g-formula. Int J Epidemiol. 2009;38:1599-611.

48. Garcia-Aymerich J, Varraso R, Danaei G, Camargo CA, Hernán MA. Incidence of adult-onset asthma after hypothetical interventions on body mass index and physical activity: an application of the parametric G-Formula. Am J Epidemiol. 2014;179:20-6.

49. Danaei G, Pan A, Hu FB, Hernán MA. Hypothetical midlife interventions in women and risk of type 2 diabetes. Epidemiology. 2013;24:122-8.

50. Lajous M, Willett WC, Robins J, Young JG, Rimm E, Mozaffarian D, et al. Changes in fish consumption in midlife and the risk of coronary heart disease in men and women. Am J Epidemiol. 2013;178:382-91.

51. Vanderweele TJ, Tchetgen TE. Mediation analysis with time-varying exposures and mediators. Harvard Univ Biostat Work Pap Ser. 2014;168:1-22.

52. Lin S-H, Young J, Logan R, Tchetgen EJT, VanderWeele TJ. Parametric mediational g-formula approach to mediation analysis with time-varying exposures, mediators, and confounders. Epidemiology. 2016;28:1.

53. Skeen S, Laurenzi CA, Gordon SL, Du Toit S, Tomlinson M, Dua T, et al. Adolescent mental health program components and behavior risk reduction: a meta-analysis. Pediatrics. 2019;144:e20183488.

54. Bhana A, Mellins CA, Petersen I, Alicea S, Myeza N, Holst H, et al. The VUKA family program: piloting a family-based psychosocial intervention to promote health and mental health among HIV infected early adolescents in South Africa. AIDS Care. 2014;26:1-11.

55. Kogan SM, Yu T, Brody GH, Chen YF, Diclemente RJ, Wingood $\mathrm{GM}$, et al. Integrating condom skills into family-centered prevention: efficacy of the strong African American families-teen program. J Adolesc Health. 2012;51:164-70.

56. Perrino T, Gonzá Lez-Soldevilla A, Pantin H, Szapocznik J. The role of families in adolescent HIV prevention: a review. Clin Child Fam Psychol Rev. 2000;3:81-96.

57. Patton GC, Sawyer SM, Santelli JS, Ross DA, Afifi R, Allen NB, et al. Our future: a Lancet commission on adolescent health and wellbeing. Lancet (London, England). 2016;387:2423-78. 
58. Rosenberg M, Pettifor A, Twine R, Hughes JP, Gomez-Olive FX, Wagner RG, et al. Evidence for sample selection effect and Hawthorne effect in behavioural HIV prevention trial among young women in a rural South African community. BMJ Open. 2018;8:e019167.

59. Stoner M, Westreich D, Ahern J, Edwards J, Gomez-Olive F, Tollman S, et al. Modeling combination interventions to prevent HIV in adolescent girls and young women in South Africa (HPTN 068). Clin Infect Dis. 2020. https://doi.org/10.1093/cid/ciaa1598.
60. Rothman KJ, Greenland S, Lash TL, eds. Modern epidemiology. Lippincott Williams \& Wilkins, Third Ed 2011.

Publisher's Note Springer Nature remains neutral with regard to jurisdictional claims in published maps and institutional affiliations. 